Military Technical College Kobry El-Kobbah, Cairo, Egypt

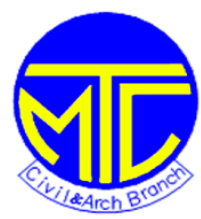

$9^{\text {th }}$ International Conference on Civil and Architecture Engineering ICCAE-9-2012

\title{
Passive earth pressure against retaining wall using log-spiral arc
}

\author{
AbdelAziz Ahmed Ali SENOON*
}

\begin{abstract}
Passive earth pressure against retaining wall depends on a number of factors such as, soil friction angle $\phi$, soil wall friction angle $\delta$, backfill angle (ground surface inclination behind wall $\beta$, inclination of wall face on horizontal $\alpha$, and surface of rupture. Several theory have been developed to over come this problem, i. e., determine the coefficient of passive earth pressure using the plane surface of rupture. One of the important parameter which effect on the coefficient of the passive earth pressure surface of rupture. In the present paper, formulation is proposed for calculating coefficient of passive earth pressure on a rigid retaining wall undergoing horizontal translation base on surface of rupture consisting log-spiral and linear segments assisted by computer program (MATLAB program used). The present study is compared with coulomb's results. The comparison between present study and coulomb's values shows the present study predict values of earth pressure much less than those of coulomb's values specially if $\delta \geq 0.3 \phi$. Those results agree with anthers researches
\end{abstract}

In order facilitate calculation coefficient of passive earth pressure, using the proposed equations, a modified coefficient of passive earth pressure is provided. It is function of $(\phi, \delta, \beta, \alpha)$.

Key words Passive earth pressure, retaining wall, surface of rupture, log- spiral

\section{Introduction}

Retaining structures are vital geotechnical structures; because the topography of the earth surface is a combination of plain, sloppy and undulating terrain. The retaining wall has traditionally been applied to free-standing walls whose resists thrust of the bank of earth as well as providing soil stability of a change of ground elevation. The design philosophy of the wall deals with the magnitude and distribution of the lateral pressure between a soil mass and wall.

*Associate Professor, Civil Engineering Dept., Faculty of Eng., Assiut University, Assiut, Egypt. 
Estimation of passive earth pressure acting on the rigid retaining wall is very important in the design of many geotechnical engineering structures; particularly retaining wall. Passive earth pressure calculations in geotechnical analysis are usually performed with the aid of Rankine[24] or Coulomb[4] theories of earth pressure based on uniform soil properties. These traditional earth pressure theories are derived from equations of equilibrium along on an assumed planner failure surface passing through the soil mass. Both assume that the distribution of the passive earth pressure exerted against the wall is triangular. However, the distribution of the earth pressure on the face of rough wall depends on the wall movement (rotation about top, rotation about bottom and horizontal translation) and is nonlinear. This is different from the assumption mode by both Rankine[24] and Coulomb[4].

The Coulomb theory is more versatile in accommodating complex configurations of backfills and loading conditions as well as frictional effects between walls and backfills. However, both theoretical and experimental studies have shown that the Coulomb assumption of plane surface sliding is not perfectly valid when the wall is rough, especially in the spassive case when interface friction is more than $1 / 3$ of internal soil friction. The curvature of the failure surface behind the wall needs to be taken into account. Hence, Coulomb's theory leads to largely overestimation of the passive earth pressure.

The Rankine's theory is applicable to the calculation of the earth pressure on a perfectly smooth and vertical wall, but most retaining walls are far from frictionless soil structure interface.

The passive earth pressure problem has been widely treated in the text books, literature and articles [1-22]. Theoretical procedures for evaluating the earth pressure using different approaches (the limit equilibrium method [11] and [8], the slip line method [5], [15], [22] and [14], the upper- and lower bound theorems of limit analysis [23] and numerical computation.

Rupaand Pise, [19] used a circular arc due to arching effect for determining the passive earth pressure coefficient. Janbu[13] used a method of slices with bearing capacity factors to calculate passive pressure resultants. These different approaches generally confirm the accuracy of the Log Spiral Theory [5] for a wide range of values of the internal soil friction and the soil-structure interface friction angle. Similarly, Martin [10] and Benmebarek et al. [17] who used FLAC ${ }^{2 \mathrm{D}}$ numerical analysis to evaluatepassive earth pressures have found fairly close agreement with Log Spiral Theory. In spite of recent published methods, the tendency today in practice is to use the values given by Caquot and Kérisel[5] and Kérisel and Absi[15].

Many studies have investigated the capacity and load-deflection relationships for walls under passive conditions using finite element and finite difference methods. Duncan and Mokwa[7] review the results of many of those studies, and report that they have generally found the log-spiral surface to accurately reflect the computed failure surface from the models. Moreover, they found that log-spiral solutions for passive 
capacity are much more compatible with results of element modeling than the Coulomb model. Smith and Griffiths [21] used the finite element method to estimate the earth pressure uses an elastic-perfectly Mohr-Coulomb constitutive model with stress redistribution achieved iteratively using a reduced integration elasto-viscoplasticity algorithm

In order to appreciate the accuracy of the present analysis, the theoretical approach of Coulomb is used for comparison.

\section{Coefficient of passive earth pressure}

Lateral earth pressure is the pressure that soil exerts in the horizontal plane. To describe the pressure a soil will exert a lateral earth pressure coefficient, $\mathrm{K}$, is used. $\mathrm{K}$ is the ratio of horizontal pressure to vertical pressure $\left(\mathrm{K}={ }^{\sigma_{h}} / \sigma_{v}\right) . \mathrm{K}$ used in geotechnical engineering analysis depends on the characteristics of its applications. There are many theories for predictions lateral earth pressure, some are empirically based, and some are analytically derived. In this section we will discus the theories for the passive earth pressure only.

\section{Coulomb's theory [4]}

Coulomb (1776) first studied the problem of the lateral earth pressure on the retaining structures. He used limit equilibrium theory, which considers the failing soil block as a free body in order to determine the limiting horizontal earth pressure. His theory treats the soil as isotropic and accounts for both internal friction at the wall-soil interface (friction angle $\delta$ )

The coefficient of the passive earth pressure based on coulomb's theory is:

$$
K_{p C}=\frac{\sin ^{2}(\alpha-\varphi)}{\sin ^{2}(\alpha) \sin (\alpha+\delta)\left[1-\sqrt{\frac{\sin (\varphi+\delta) \sin (\varphi+\beta)}{\sin (\alpha+\hat{\delta}) \sin (\alpha+\beta)}}\right]^{2}}
$$

Where:

$\mathrm{K}_{\mathrm{pc}}$ the coefficient of the passive earth pressure based on coulomb's theory

$\beta=$ angle between backfill surface lines and a horizontal line

$\varphi=$ friction angle of the backfill soil

$\alpha=$ angle between a horizontal line and the back face of the wall

$\delta=$ angle of wall friction

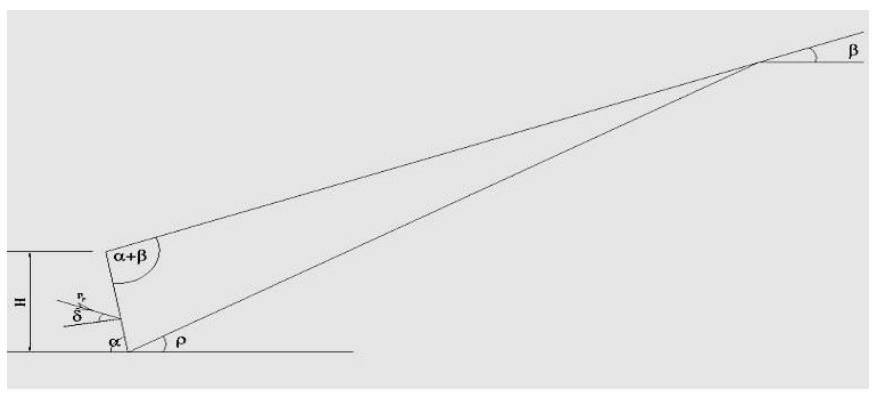




\section{Rankine's theory}

\section{Fig. (1)Schematic forces acting on a retaining wall}

The Rankine(1857) method of evaluating passive pressure is a special case of the conditions considered by Coulomb. In particular, Rankine assumes that there is no friction at the wall-soil interface $(\delta=0)$. The coefficient of Rankine's passive earth pressure can be computed as:

$K_{p R}=\cos \beta \frac{\cos \beta+\sqrt{\cos ^{2}(\beta)-\cos ^{2}(\varphi)}}{\cos \beta-\sqrt{\cos ^{2}(\beta)-\cos ^{2}(\varphi)}}$

When the embankment slope angle $\beta$ equal zero, $\mathrm{K}_{\mathrm{pR}}=\tan ^{2}(45+\varphi / 2)$.

\section{Properties of logarithmic spiral (after [6])}

The equation of the logarithmic spiral generally used in solving problems in soil mechanics is of the form

Where $\mathrm{r}=$ radius of the spiral

$$
r=r_{o \theta}^{\theta \tan \varphi}
$$

$r_{o}=$ staring radius at $\theta=0.0$

$\phi=$ angle of friction of soil

$\theta=$ angle between $r$ and $r_{\circ}$

the basic parameters of a logarithmic spiral are shown in $\operatorname{Fig}(2)$., in which $\mathrm{O}$ is the center of the spiral. The area of the sector $\mathrm{OAB}$ is given by

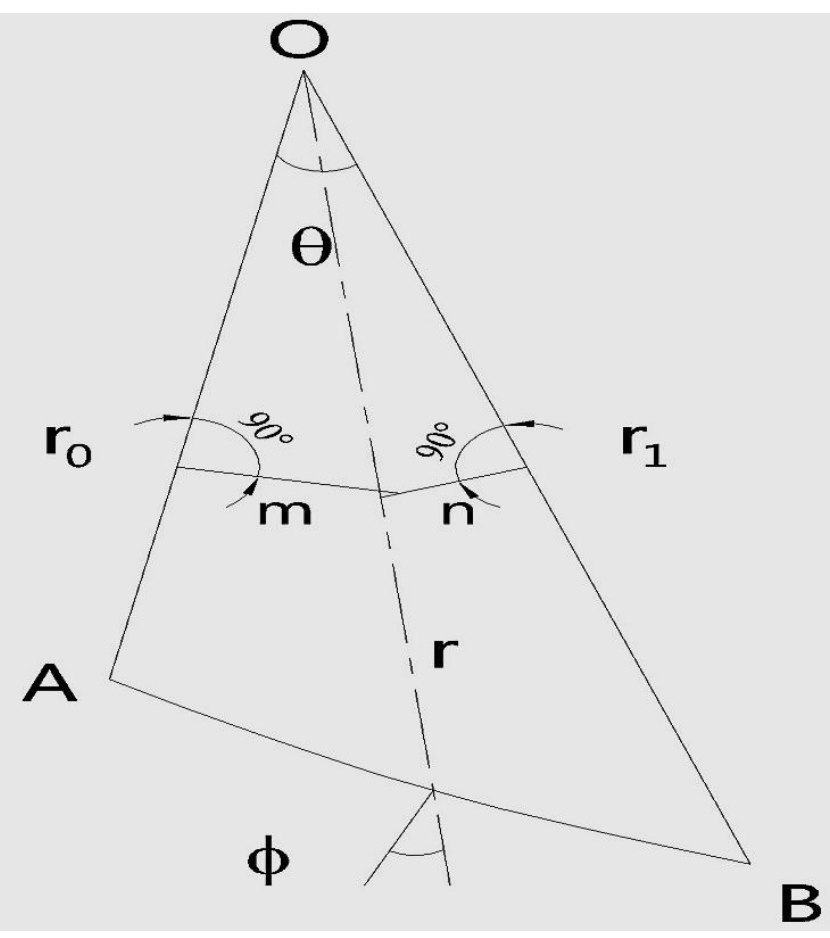


Fig.(2) General parameters of a logarithmic spiral (after Das [6])

$A=\int_{0}^{\theta} \frac{1}{2} r(r d \theta)$

Substituting the values of $\mathrm{r}$ from $\mathrm{Eq}(3)$ into $\mathrm{Eq}(4)$, we get

$$
\begin{aligned}
& A=\int_{0}^{\theta_{1}} \frac{1}{2} r_{0}^{2} e^{2 \theta \tan \emptyset} d \theta \\
& =\frac{r_{1-r_{0}^{2}}^{2}}{4 \tan \varphi}
\end{aligned}
$$

The location of the centroid can be defined by the distances $\bar{m}$ and $\bar{n}$ Fig (2)., measured from $\mathrm{OA}$ and $\mathrm{OB}$ respectively, and can be given by the following equations (Hijab, 1956):

$$
\begin{aligned}
& \bar{m}=\frac{4}{3} r_{\circ} \frac{\tan \varphi}{\left(9 \tan ^{2} \varphi+1\right)}\left[\frac{\left(\frac{r_{1}}{r_{0}}\right)^{\mathrm{I}}(3 \tan \varphi \sin \theta-\cos \theta)+1}{\left(\frac{r_{1}}{r_{0}}\right)^{2}-1}\right](6) \\
& \bar{n}=\frac{4}{3} r_{\circ} \frac{\tan \emptyset}{\left(9 \tan ^{2} \emptyset+1\right)}\left[\frac{\left(\frac{r_{1}}{r_{0}}\right)^{\mathrm{s}}-3 \tan \emptyset \sin \theta-\cos \varphi}{\left(\frac{r_{1}}{r_{0}}\right)^{2}-1}\right] \text { (7) }
\end{aligned}
$$

Another important property of the logarithmic spiral defined by Eq. is that any radial line makes an angle $\phi$ with the normal to the curve drawn at the point where to radial line and spiral intersect. This basic is particularly useful in solving problem related to lateral earth pressure.

Procedure for determination of passive earth pressure (cohesionless backfill)

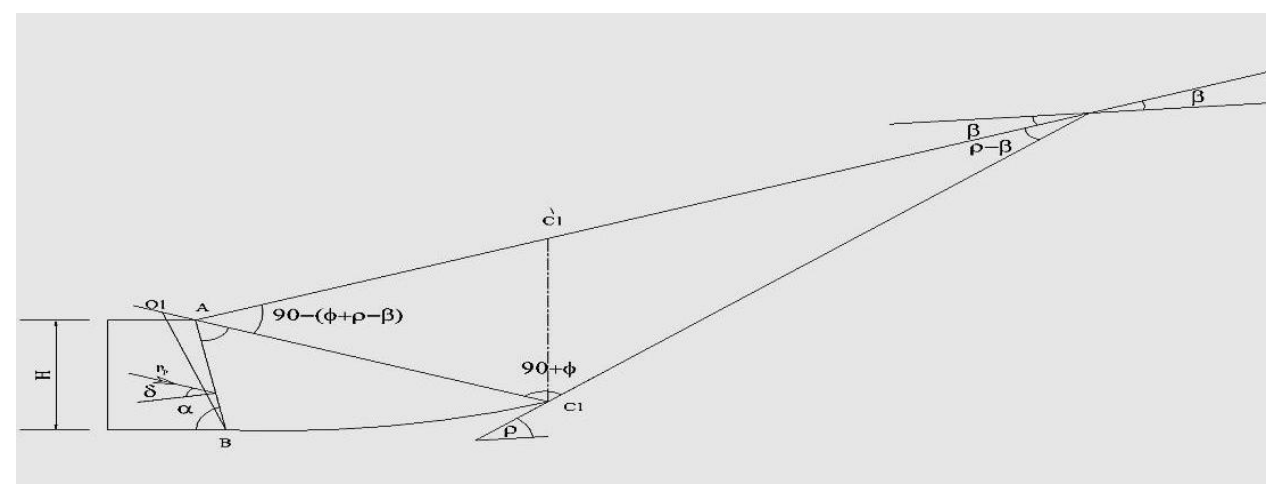

(a) 

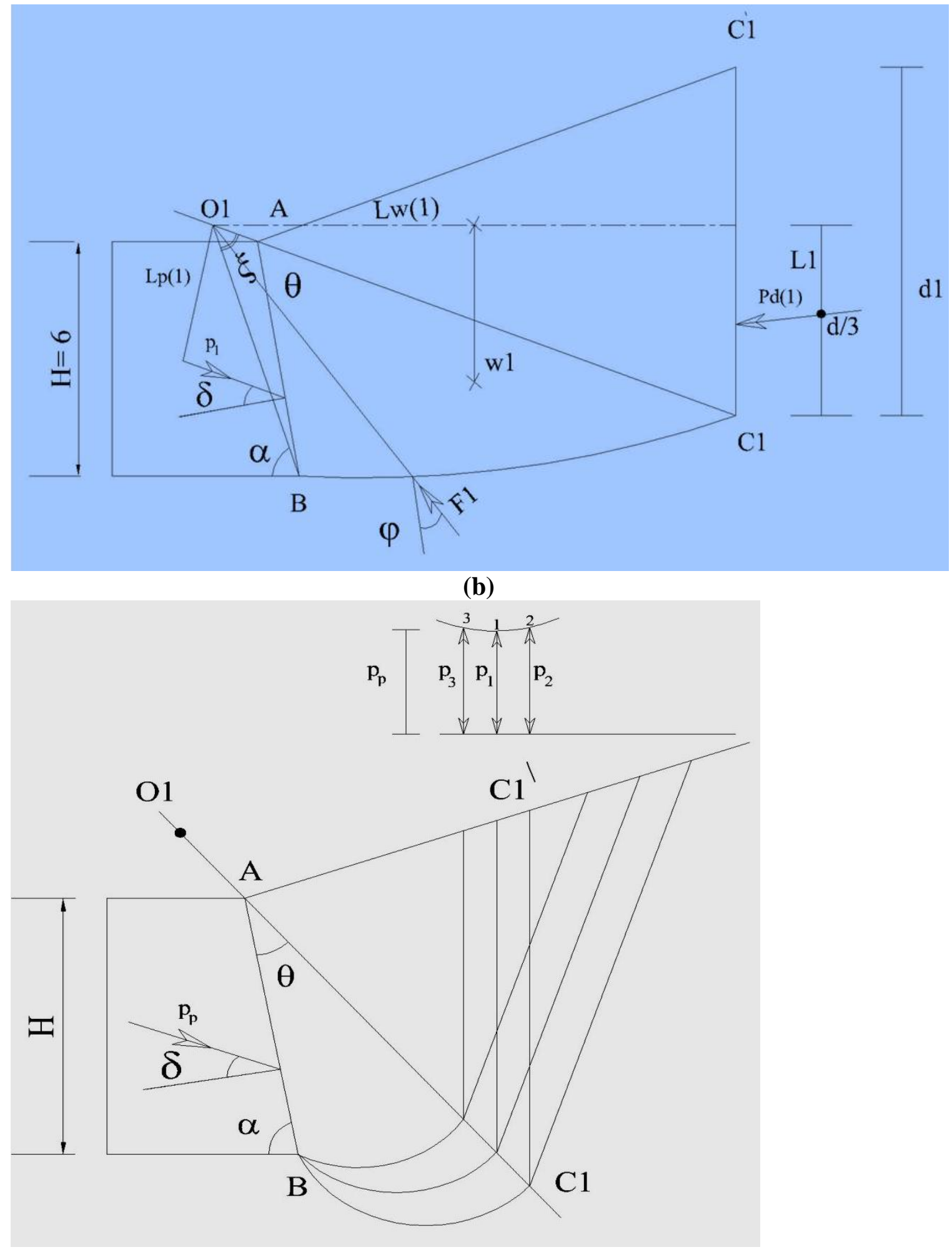

(c)

Fig. (3)Passive earth pressure against retaining wall with curved failure surface 
Fig.(3a) shows the curved failure in the granular backfill of a retaining wall of height $\mathrm{H}$. the shear strength of the granular backfill is expressed as $\tau_{f}=\sigma \tan \varphi$. The curved lower portion $\mathrm{BC}_{1}$ of the failure wedge is an arc of logarithmic spiral defined by Eq.(3) The center of the $\log$ spiral lies on the line $\mathrm{C}_{1} \mathrm{~A}$ (not necessarily within the limits of the points $\left(\mathrm{C}\right.$ and $\mathrm{A}$ ). the upper portion $\mathrm{C}_{1} \mathrm{D}$ is a straight line that make angle of $(\rho)$ degrees with the horizontal. $(\rho)$ defined by the following eq.

$\rho=\omega-\varphi$

Where $\omega$ as follows:

$\tan \omega$

$=\frac{\tan (\varphi+\beta)+\sqrt{\tan (\varphi+\beta)[\tan (\emptyset+\beta)+\cot (\varphi+\alpha)][1+\tan (\delta-\alpha) \cot (\varphi+\alpha)]}}{1+\tan (\delta-\alpha)[\tan (\varphi+\beta)+\cot (\varphi+\alpha)]}$

The soil in the zone $\mathrm{AC}_{1} \mathrm{D}$ is in Rankine's passive state.Fig.(3) shows the procedure for evaluating the passive resistance by trail wedges (Terzaghi and Peck, 1967). The retaining wall is first drawn to scale as shown in Fig.(3a). The line $\mathrm{C}_{1} \mathrm{~A}$ is drawing in such a way that it makes an angle of $(\rho-\beta)$ degrees with the surface of the backfill. $\mathrm{BC}_{1} \mathrm{D}_{1}$ is trials wedge in which $\mathrm{BC}_{1}$ is the arc of a logarithmic spiral according to the equation Eq. (3). $\mathrm{O}_{1}$ is the center of the spiral (note: $\mathrm{O}_{1} \mathrm{~B}=\mathrm{r}_{\mathrm{o}}$ and $\mathrm{O}_{1} \mathrm{C}_{1}=\mathrm{r}_{1}$ and angle $\mathrm{BO}_{1} \mathrm{C}_{1}=$ angle between two radial lines of spiral (refer to Fig. (3b). Now let us consider the stability of the soil mass $\mathrm{ABC}_{1} C_{1}^{*}$ (Fig. (3b). For equilibrium the following forces per unit length of the wall are to be considered

1- Weight of the soil in zone $\mathrm{ABC}_{1} C_{1}^{\sigma}=\mathrm{W}_{1}=(\Upsilon)\left(\right.$ area of $\left.\mathrm{ABC}_{1} C_{1}^{\sigma}\right)(1)$

2 -The vertical face, $C_{1} C_{1}^{*}$, is the zone of Rankine's passive state; hence, the force acting on this face is

$P_{d(1)}=\frac{1}{2} \gamma\left(d_{1}\right)^{2} \tan ^{2}\left(45+\frac{\emptyset}{2}\right)$

Where $\mathrm{d}_{1}=\mathrm{C}_{1} C_{1_{1}}^{*} P_{d(1)}$ acts parallel to the ground surface at a distance of $\mathrm{d}_{1} / 3$ measured vertically upward from $\mathrm{C}_{1}$

3- $\mathrm{F}_{1}$ is the resultant of the shear and normal forces that act along the surface of sliding $\mathrm{BC}_{1}$. At any point on the curve, according to the property of the logarithmic spiral, a radial line makes an angle $\phi$ with the normal. Because the resultant, $F_{1}$ makes an angle $\phi$ with the normal to the spiral at its point of application, its line of application will coincide with a radial line and will pass through the point $\mathrm{O}_{1}$.

4- $\mathrm{P}_{1}$ is the passive force per unit length of the wall. It acts at distance of $\mathrm{H} / 3$ measured vertically from the bottom of the wall. The direction of the force $\mathrm{P}_{1}$ is inclined at an angle $\delta$ with the normal drawn to the back face of the wall.

Now, taking the moment of $\mathrm{W}_{1}, P_{d(1)}, \mathrm{F}_{1}$ and $\mathrm{P}_{1}$ about the point $\mathrm{O}_{1}$ for equilibrium, we have

$W_{1}\left[l_{w(1)}\right]+P_{d(1)}\left[l_{1}\right]+F_{1}[0]=P_{1}\left[l_{p(1)}\right]$ 
$P_{1}=\frac{1}{l_{p(1)}}\left[W_{1} l_{w(1)}+P_{d(1)} l_{1}\right]$

where $l_{w(1)}, l_{1}$ and $l_{p(1)}$ are moment arms for the forces $W_{1}, P_{d(1)}$ and $P_{1}$, respectively.

Thepreceding procedure for finding the trial passive force per unit length of the wall is repeated for several trial wedges such as those shown in Fig. (3c). Let $\mathrm{P}_{1}, \mathrm{P} 2, \mathrm{P} 3, \ldots . . \mathrm{P}_{\mathrm{n}}$ be the forces that corresponding to trial wedges $1,2,3, \ldots \ldots, \mathrm{n}$. The lowest point of the smooth curve defines the actual passive forces, $\mathrm{P}_{\mathrm{p}}$, per unit length of the wall. The coefficient of the passive earth pressure $\mathrm{K}_{\mathrm{p}}=2 \mathrm{P}_{\mathrm{p}} / \gamma \mathrm{H}^{2}$.

It is worthwhile mentioning here that when we did not get a clear minimum coefficient of passive earth pressure, take $\mathrm{k}_{\mathrm{p}}$ (min.) corresponding the angle $\mathrm{BO}_{1} \mathrm{C}$ between $\mathrm{O}_{1} B=r_{0}$ and $\mathrm{O}_{1} \mathrm{C}_{1}=\mathrm{r}_{1}$ equal to $(\rho-\beta)$, where $\rho$ inclined angle of tangent on the horizontal and $\beta$ inclined of the ground surface

\section{Main goal of the present work}

The main goal of the present work is the transfer the shown case of passive earth pressure against rigid retaining wall using surface of rupture consisting log- spiral curve and linear segments as depicted in Fig.(3) into group of equations can solved easily by computer with high accuracy.

\section{Parameters used in the program}

Wall geometry: height of the wall, $\mathrm{H}$, inclination of the back wall on the horizontal, $\alpha$, $=90,80$ and 70

Ground surface slope of the backfill $\beta=(0,0.2,0.4,0.6$ and 0.8$) \phi$

Soil properties: angle of internal friction, $\phi,=5,10,15,20,25,30,35,40$ and 45

Friction between wall and soil $\delta=(0,0.2,0.4,0.6,0.8$ and 1$) \phi$

\section{Procedure of calculations}

1- For a constant $\alpha=90 ; \phi$ is changed nine times $(5,10,15,20,25,30,35,40$ and 45) and the corresponding minimum coefficient of passive earth pressure are found using proposed as discuss before.

2 - The value $\delta$ is change six times and step No. 1 is repeated.

3 - The value $\beta$ is changed five times and steps No. 1 and 2 are repeated.

4- For $\alpha=90,80$ and 70 degree steps No. 1, 2 and 3 are repeated.

5- Results for steps No. 1, 2, 3 and 4 are shown in Table 1, 2 and 3 
Table 1 Coefficient of passive earth pressure using log-spiral curve failure surface at $\alpha=$ $90^{\circ}$

\begin{tabular}{|c|c|c|c|c|c|c|}
\hline \multirow[t]{3}{*}{$\phi$} & \multicolumn{6}{|c|}{$\beta=0.0$} \\
\hline & \multicolumn{6}{|c|}{$\delta$} \\
\hline & 0 & $0.2 \phi$ & $0.4 \phi$ & $0.6 \phi$ & $0.8 \phi$ & $\phi$ \\
\hline 5 & 1.218 & 1.225 & 1.233 & 1.233 & 1.240 & 1.247 \\
\hline 10 & 1.495 & 1.510 & 1.527 & 1.547 & 1.575 & 1.598 \\
\hline 15 & 1.811 & 1.862 & 1.918 & 1.971 & 2.039 & 2.109 \\
\hline 20 & 2.224 & 2.310 & 2.428 & 2.556 & 2.709 & 2.892 \\
\hline 25 & 2.712 & 2.893 & 3.120 & 3.395 & 3.740 & 4.175 \\
\hline 30 & 3.319 & 3.672 & 4.100 & 4.661 & 5.429 & 6.425 \\
\hline 35 & 4.120 & 4.712 & 5.532 & 6.703 & 8.450 & 10.417 \\
\hline 40 & 5.140 & 6.168 & 7.746 & 10.301 & 14.089 & 18.047 \\
\hline 45 & 6.484 & 8.305 & 11.427 & 17.381 & 25.307 & 34.026 \\
\hline \multirow[t]{3}{*}{$\phi$} & \multicolumn{6}{|c|}{$\beta=0.2$} \\
\hline & \multicolumn{6}{|c|}{$\delta$} \\
\hline & 0 & $0.2 \phi$ & $0.4 \phi$ & $0.6 \phi$ & $0.8 \phi$ & $\phi$ \\
\hline 5 & 1.255 & 1.252 & 1.259 & 1.266 & 1.273 & 1.273 \\
\hline 10 & 1.567 & 1.594 & 1.609 & 1.628 & 1.656 & 1.679 \\
\hline 15 & 1.987 & 2.022 & 2.080 & 2.143 & 2.213 & 2.286 \\
\hline 20 & 2.519 & 2.624 & 2.748 & 2.883 & 3.056 & 3.260 \\
\hline 25 & 3.208 & 3.427 & 3.695 & 4.012 & 4.414 & 4.924 \\
\hline 30 & 4.156 & 4.564 & 5.108 & 5.824 & 6.771 & 7.977 \\
\hline 35 & 5.458 & 6.280 & 7.369 & 8.940 & 11.238 & 13.722 \\
\hline 40 & 7.379 & 8.919 & 11.202 & 14.970 & 20.097 & 25.462 \\
\hline 45 & 10.203 & 13.274 & 18.356 & 27.648 & 39.359 & 51.956 \\
\hline \multirow[t]{3}{*}{$\phi$} & \multicolumn{6}{|c|}{$\beta=0.4$} \\
\hline & \multicolumn{6}{|c|}{$\delta$} \\
\hline & 0 & $0.2 \phi$ & $0.4 \phi$ & $0.6 \phi$ & $0.8 \phi$ & $\phi$ \\
\hline 5 & 1.282 & 1.288 & 1.284 & 1.291 & 1.297 & 1.304 \\
\hline 10 & 1.653 & 1.664 & 1.691 & 1.706 & 1.734 & 1.755 \\
\hline 15 & 2.132 & 2.201 & 2.241 & 2.306 & 2.378 & 2.458 \\
\hline 20 & 2.813 & 2.922 & 3.070 & 3.222 & 3.403 & 3.620 \\
\hline 25 & 3.743 & 4.007 & 4.295 & 4.658 & 5.113 & 5.690 \\
\hline 30 & 5.098 & 5.589 & 6.237 & 7.091 & 8.233 & 9.642 \\
\hline 35 & 7.088 & 8.126 & 9.561 & 11.566 & 14.446 & 17.479 \\
\hline 40 & 10.262 & 12.459 & 15.636 & 20.834 & 27.556 & 34.460 \\
\hline 45 & 15.681 & 20.272 & 28.161 & 41.812 & 58.329 & 75.369 \\
\hline \multirow[t]{3}{*}{$\phi$} & \multicolumn{6}{|c|}{$\beta=0.6$} \\
\hline & \multicolumn{6}{|c|}{$\delta$} \\
\hline & 0 & $0.2 \phi$ & $0.4 \phi$ & $0.6 \phi$ & $0.8 \phi$ & $\phi$ \\
\hline 5 & 1.306 & 1.312 & 1.317 & 1.313 & 1.319 & 1.324 \\
\hline 10 & 1.720 & 1.745 & 1.755 & 1.781 & 1.796 & 1.824 \\
\hline 15 & 2.295 & 2.342 & 2.397 & 2.458 & 2.539 & 2.616 \\
\hline 20 & 3.114 & 3.246 & 3.370 & 3.541 & 3.724 & 3.948 \\
\hline 25 & 4.323 & 4.592 & 4.888 & 5.293 & 5.782 & 6.415 \\
\hline 30 & 6.111 & 6.688 & 7.433 & 8.384 & 9.703 & 11.289 \\
\hline 35 & 8.978 & 10.311 & 11.962 & 14.419 & 17.869 & 21.400 \\
\hline 40 & 14.053 & 16.804 & 20.921 & 27.694 & 36.103 & 44.495 \\
\hline 45 & 23.270 & 29.626 & 41.012 & 60.019 & 82.058 & 103.672 \\
\hline
\end{tabular}


Table 1 Coefficient of passive earth pressure using log-spiral curve failure surface at $\alpha=$ $90^{\circ}$ (continous)

\begin{tabular}{|c|c|c|c|c|c|c|}
\hline \multirow{2}{*}{$\phi$} & \multicolumn{6}{|c|}{$\beta=0.8$} \\
\cline { 2 - 7 } & \multicolumn{7}{|c|}{$\delta$} \\
\cline { 2 - 7 } & 0 & $0.2 \phi$ & $0.4 \phi$ & $0.6 \phi$ & $0.8 \phi$ & $\phi$ \\
\hline 5 & 1.327 & 1.332 & 1.336 & 1.340 & 1.335 & 1.339 \\
\hline 10 & 1.779 & 1.801 & 1.822 & 1.830 & 1.854 & 1.868 \\
\hline 15 & 2.448 & 2.485 & 2.530 & 2.583 & 2.646 & 2.729 \\
\hline 20 & 3.397 & 3.517 & 3.627 & 3.791 & 3.981 & 4.196 \\
\hline 25 & 4.838 & 5.094 & 5.414 & 5.816 & 6.324 & 6.973 \\
\hline 30 & 7.134 & 7.696 & 8.511 & 9.528 & 10.934 & 12.604 \\
\hline 35 & 11.009 & 12.400 & 14.249 & 17.039 & 20.899 & 24.723 \\
\hline 40 & 18.046 & 21.292 & 26.249 & 34.531 & 44.296 & 53.707 \\
\hline 45 & 32.072 & 40.413 & 55.714 & 80.184 & 107.414 & 132.636 \\
\hline
\end{tabular}

Table 2 Coefficient of passive earth pressure using log-spiral curve failure surface at $\alpha=$ $80^{\circ}$

\begin{tabular}{|c|c|c|c|c|c|c|}
\hline \multirow[t]{3}{*}{$\phi$} & \multicolumn{6}{|c|}{$\beta=0.0$} \\
\hline & \multicolumn{6}{|c|}{$\delta$} \\
\hline & 0 & $0.2 \phi$ & $0.4 \phi$ & $0.6 \phi$ & $0.8 \phi$ & $\phi$ \\
\hline 5 & 1.253 & 1.253 & 1.2538 & 1.2548 & 1.256 & 1.2575 \\
\hline 10 & 1.568 & 1.569 & 1.5641 & 1.5763 & 1.5776 & 1.5908 \\
\hline 15 & 1.850 & 1.876 & 1.8977 & 1.9319 & 1.9644 & 2.0035 \\
\hline 20 & 2.218 & 2.257 & 2.3294 & 2.4063 & 2.4993 & 2.6101 \\
\hline 25 & 2.624 & 2.750 & 2.8837 & 3.0558 & 3.2707 & 3.5347 \\
\hline 30 & 3.136 & 3.361 & 3.6346 & 3.9872 & 4.4435 & 5.0564 \\
\hline 35 & 3.792 & 4.158 & 4.6703 & 5.3675 & 6.3587 & 7.7397 \\
\hline 40 & 4.569 & 5.218 & 6.1662 & 7.565 & 9.8053 & 12.6693 \\
\hline 45 & 5.561 & 6.673 & 8.4238 & 11.373 & 16.5068 & 22.5112 \\
\hline \multirow[t]{3}{*}{$\phi$} & \multicolumn{6}{|c|}{$\beta=0.2$} \\
\hline & \multicolumn{6}{|c|}{$\delta$} \\
\hline & 0 & $0.2 \phi$ & $0.4 \phi$ & $0.6 \phi$ & $0.8 \phi$ & $\phi$ \\
\hline 5 & 1.286 & 1.287 & 1.287 & 1.288 & 1.289 & 1.290 \\
\hline 10 & 1.648 & 1.661 & 1.655 & 1.661 & 1.668 & 1.677 \\
\hline 15 & 2.030 & 2.058 & 2.079 & 2.115 & 2.148 & 2.188 \\
\hline 20 & 2.525 & 2.574 & 2.653 & 2.735 & 2.843 & 2.963 \\
\hline 25 & 3.133 & 3.278 & 3.440 & 3.643 & 3.894 & 4.201 \\
\hline 30 & 3.949 & 4.225 & 4.582 & 5.023 & 5.591 & 6.348 \\
\hline 35 & 5.040 & 5.575 & 6.278 & 7.226 & 8.544 & 10.360 \\
\hline 40 & 6.600 & 7.591 & 8.985 & 11.037 & 14.284 & 18.265 \\
\hline 45 & 8.809 & 10.687 & 13.584 & 18.384 & 26.352 & 35.386 \\
\hline
\end{tabular}


Table 2 Coefficient of passive earth pressure using log-spiral curve failure surface at $\alpha=80^{\circ}$ (continuous)

\begin{tabular}{|c|c|c|c|c|c|c|}
\hline \multirow[t]{3}{*}{$\phi$} & \multicolumn{6}{|c|}{$\beta=0.4$} \\
\hline & \multicolumn{6}{|c|}{$\delta$} \\
\hline & 0 & $0.2 \phi$ & $0.4 \phi$ & $0.6 \phi$ & $0.8 \phi$ & $\phi$ \\
\hline 5 & 1.318 & 1.318 & 1.318 & 1.319 & 1.319 & 1.320 \\
\hline 10 & 1.667 & 1.664 & 1.678 & 1.693 & 1.709 & 1.718 \\
\hline 15 & 2.042 & 2.079 & 2.123 & 2.183 & 2.237 & 2.298 \\
\hline 20 & 2.540 & 2.635 & 2.749 & 2.882 & 3.031 & 3.215 \\
\hline 25 & 3.160 & 3.366 & 3.625 & 3.944 & 4.325 & 4.814 \\
\hline 30 & 3.969 & 4.407 & 4.949 & 5.668 & 6.638 & 7.798 \\
\hline 35 & 5.075 & 5.915 & 7.078 & 8.773 & 11.128 & 13.520 \\
\hline 40 & 6.608 & 8.256 & 10.824 & 15.078 & 20.217 & 25.471 \\
\hline \multirow[t]{4}{*}{45} & 8.876 & 12.191 & 18.524 & 28.704 & 40.596 & 53.300 \\
\hline & \multicolumn{6}{|c|}{$\beta=0.6$} \\
\hline & \multicolumn{6}{|c|}{$\delta$} \\
\hline & 0 & $0.2 \phi$ & $0.4 \phi$ & $0.6 \phi$ & $0.8 \phi$ & $\phi$ \\
\hline 5 & 1.3472 & 1.347 & 1.3469 & 1.3469 & 1.3471 & 1.3475 \\
\hline 10 & 1.7065 & 1.708 & 1.7263 & 1.7445 & 1.7541 & 1.7746 \\
\hline 15 & 2.1263 & 2.1745 & 2.228 & 2.287 & 2.3448 & 2.4195 \\
\hline 20 & 2.6778 & 2.8046 & 2.9358 & 3.0932 & 3.2796 & 3.4969 \\
\hline 25 & 3.4052 & 3.6671 & 3.9936 & 4.3817 & 4.8789 & 5.4941 \\
\hline 30 & 4.3918 & 4.9466 & 5.6697 & 6.6465 & 7.9508 & 9.3019 \\
\hline 35 & 5.7766 & 6.9429 & 8.6207 & 11.164 & 14.0912 & 16.9258 \\
\hline 40 & 7.863 & 10.3493 & 14.6983 & 20.709 & 27.1968 & 33.8051 \\
\hline \multirow[t]{4}{*}{45} & 11.2451 & 17.0734 & 28.4959 & 42.516 & 58.8074 & 75.5015 \\
\hline & \multicolumn{6}{|c|}{$\beta=0.8$} \\
\hline & \multicolumn{6}{|c|}{$\delta$} \\
\hline & 0 & $0.2 \phi$ & $0.4 \phi$ & $0.6 \phi$ & $0.8 \phi$ & $\phi$ \\
\hline 5 & 1.3745 & 1.3734 & 1.3724 & 1.3713 & 1.3704 & 1.3697 \\
\hline 10 & 1.739 & 1.7433 & 1.7635 & 1.7832 & 1.7941 & 1.8156 \\
\hline 15 & 2.1967 & 2.2526 & 2.3006 & 2.3679 & 2.4341 & 2.5116 \\
\hline 20 & 2.7967 & 2.9325 & 3.091 & 3.2676 & 3.4801 & 3.7326 \\
\hline 25 & 3.606 & 3.9211 & 4.2943 & 4.775 & 5.3872 & 6.0744 \\
\hline 30 & 4.739 & 5.433 & 6.3547 & 7.6607 & 9.1817 & 10.6155 \\
\hline 35 & 6.4319 & 7.9737 & 10.4122 & 13.6467 & 16.9049 & 20.0532 \\
\hline 40 & 9.1701 & 12.9573 & 19.4407 & 26.598 & 34.3447 & 41.8913 \\
\hline 45 & 14.1789 & 25.3723 & 40.2277 & 58.3373 & 78.8112 & 82.6926 \\
\hline
\end{tabular}


Table 3 Coefficient of passive earth pressure using log-spiral curve failure surface at $\alpha=$ $70^{\circ}$

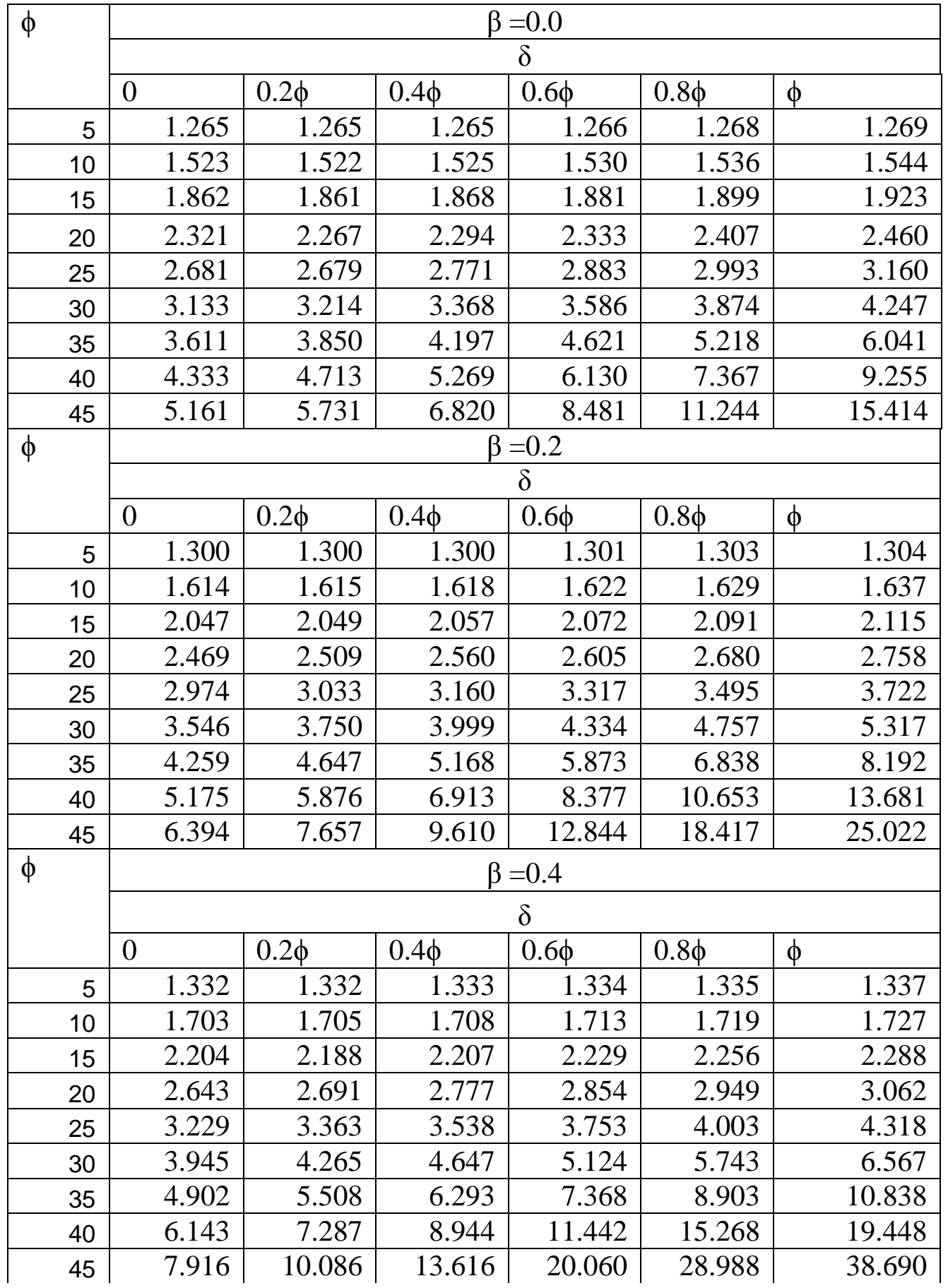


Table 3 Coefficient of passive earth pressure using log-spiral curve failure surface at $\alpha=70^{\circ}$ (continuous)

\begin{tabular}{|c|c|c|c|c|c|c|}
\hline & \multicolumn{6}{|c|}{$\beta=0.6$} \\
\hline & \multicolumn{6}{|c|}{$\delta$} \\
\hline & 0 & $0.2 \phi$ & $0.4 \phi$ & $0.6 \phi$ & $0.8 \phi$ & $\phi$ \\
\hline 5 & 1.363 & 1.364 & 1.364 & 1.365 & 1.366 & 1.367 \\
\hline 10 & 1.791 & 1.792 & 1.795 & 1.799 & 1.805 & 1.811 \\
\hline 15 & 2.293 & 2.294 & 2.326 & 2.360 & 2.385 & 2.428 \\
\hline 20 & 2.809 & 2.890 & 2.984 & 3.079 & 3.207 & 3.348 \\
\hline 25 & 3.487 & 3.670 & 3.901 & 4.183 & 4.517 & 4.933 \\
\hline 30 & 4.376 & 4.792 & 5.310 & 5.963 & 6.836 & 7.926 \\
\hline 35 & 5.570 & 6.403 & 7.547 & 9.153 & 11.417 & 13.841 \\
\hline 40 & 7.264 & 8.959 & 11.546 & 15.769 & 21.044 & 26.431 \\
\hline \multirow[t]{4}{*}{45} & 9.785 & 13.346 & 19.925 & 30.654 & 43.218 & 56.680 \\
\hline & \multicolumn{6}{|c|}{$\beta=0.8$} \\
\hline & \multicolumn{6}{|c|}{$\delta$} \\
\hline & 0 & $0.2 \phi$ & $0.4 \phi$ & $0.6 \phi$ & $0.8 \phi$ & $\phi$ \\
\hline 5 & 1.393 & 1.393 & 1.393 & 1.393 & 1.393 & 1.393 \\
\hline 10 & 1.876 & 1.876 & 1.877 & 1.879 & 1.881 & 1.885 \\
\hline 15 & 2.372 & 2.386 & 2.427 & 2.455 & 2.502 & 2.543 \\
\hline 20 & 2.933 & 3.045 & 3.150 & 3.275 & 3.422 & 3.595 \\
\hline 25 & 3.705 & 3.958 & 4.238 & 4.572 & 4.985 & 5.510 \\
\hline 30 & 4.747 & 5.276 & 5.933 & 6.796 & 7.964 & 9.227 \\
\hline 35 & 6.207 & 7.327 & 8.881 & 11.226 & 14.032 & 16.772 \\
\hline 40 & 8.372 & 10.822 & 14.916 & 20.838 & 27.230 & 33.677 \\
\hline 45 & 11.967 & 17.830 & 29.230 & 43.394 & 59.907 & 76.544 \\
\hline
\end{tabular}

\section{Analysis and discussion}

The discussion illustrates the effect of the parameters study on the coefficient of passive earth pressure. The main investigated parameters are:-

- Angle of internal friction of soil

- Interface friction angle between soil and wall

- Ground surface slope

- Inclined of back surface

A comparison was made between the results of present work and some researches using different surface failure, to evaluate the coefficient of the passive earth pressure. The deduced formula for calculation $\mathrm{k}_{\mathrm{p}}$ corresponding to Coulomb's coefficient.

Relation between $\varphi$ and $\mathrm{K}_{\mathrm{p}}$

The relation between $\varphi$ and $\mathrm{K}_{\mathrm{p}}$ is plotted and shown Figs (4-5), it is clear that with increasing $\varphi$ the value of $\mathrm{K}_{\mathrm{p}}$ increases, and $\mathrm{K}_{\mathrm{p}}$ increasing with increases $\delta$ for constant value of $\beta$. Figs (4-5) haves the same trend for the given values of $\beta=(0.0,0.8) \varphi$ 


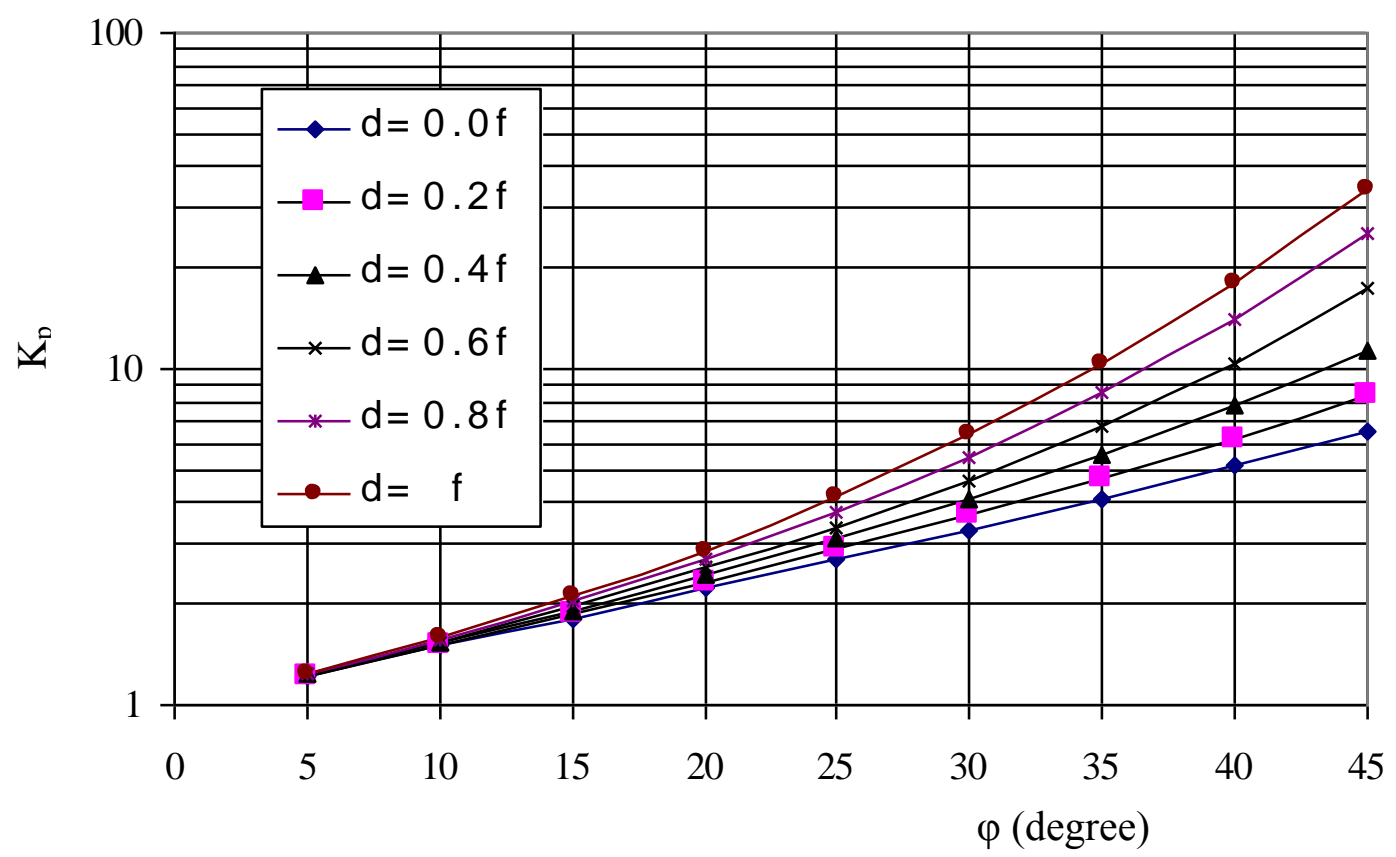

Fig.(4) $K_{p}$ versus $\varphi$ at $\beta=0.0 \varphi$ and $\propto=90$

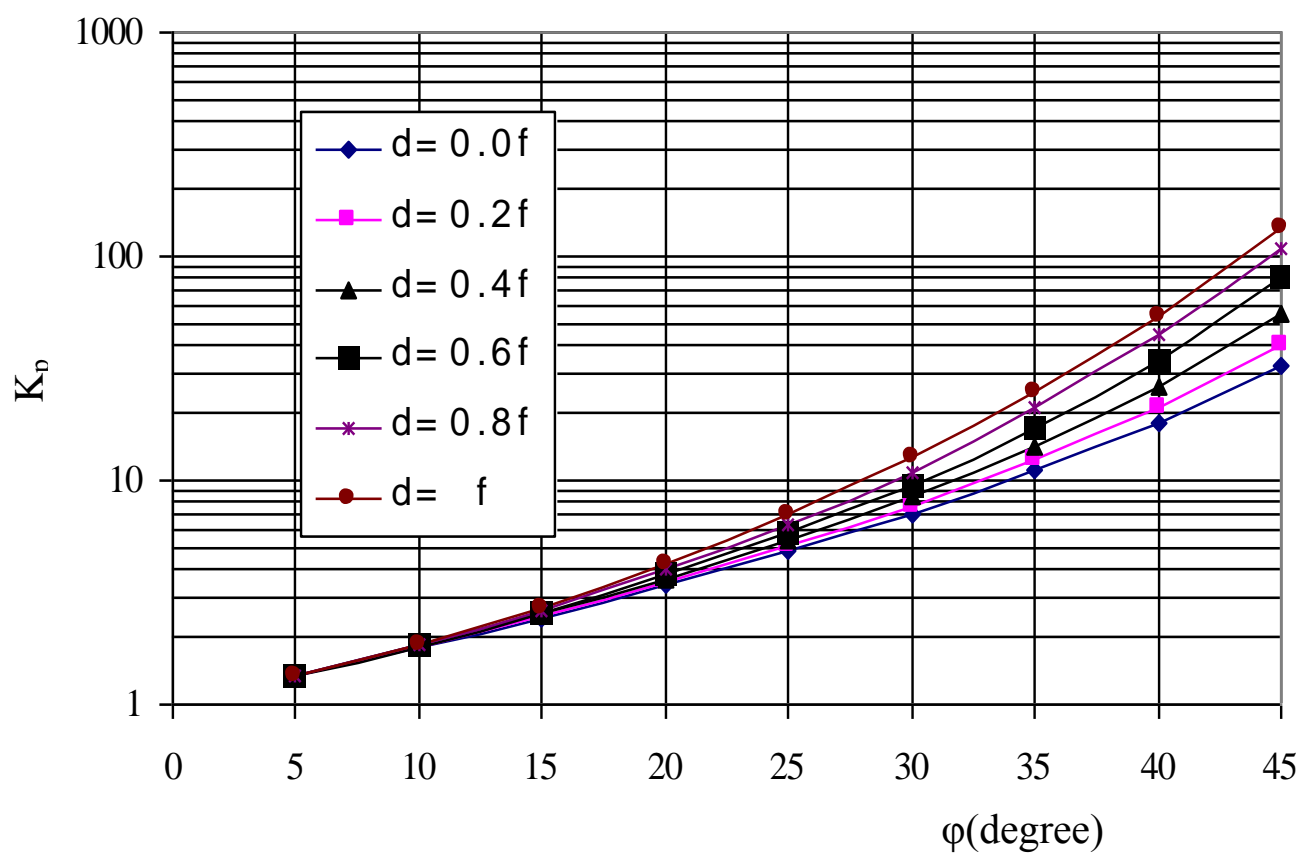

Fig.(5) $\mathrm{K}_{\mathrm{p}}$ versus $\varphi$ at $\beta=0.8 \varphi$ and $\alpha=90$ 


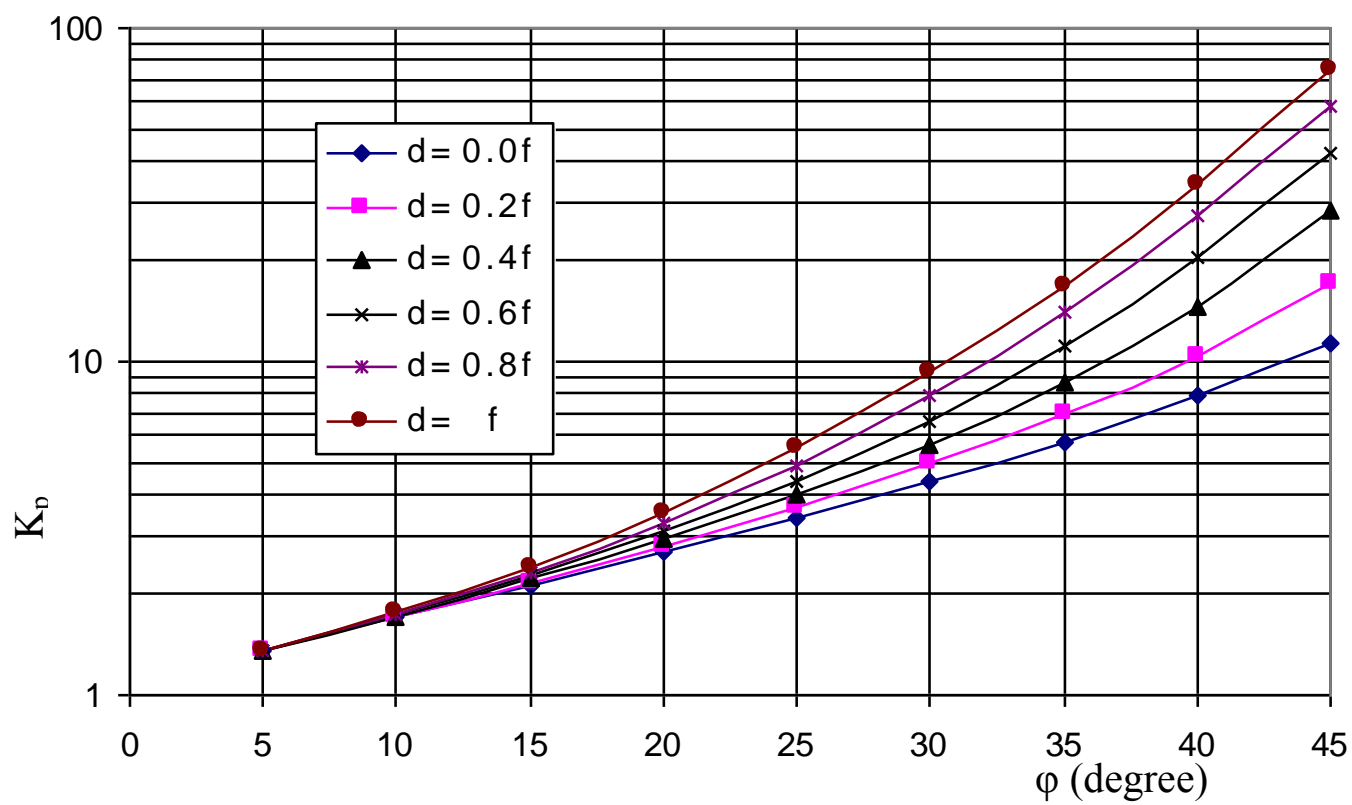

Fig.(6) $K_{p}$ versus $\varphi$ at $\beta=0.8 \varphi$ and $\alpha=80$

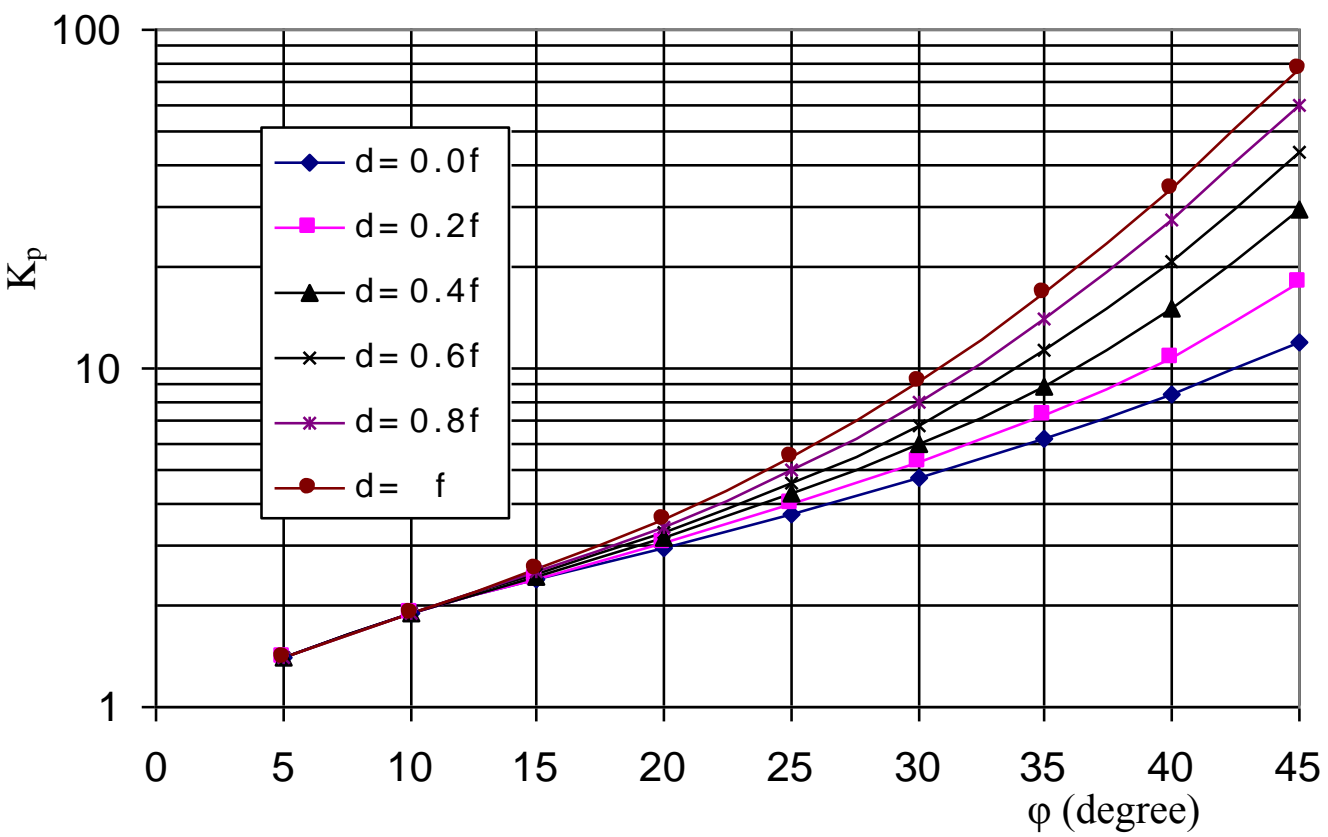

Fig.(7) $\mathrm{K}_{\mathrm{p}}$ versus $\varphi$ at $\beta=0.8 \varphi$ and $\alpha=70^{\circ}$

Figs.(5-7) show the relation between $K_{p}$ and $\varphi$ at $\beta=0.8 \varphi$ for different values $\alpha$. It is evident that $\mathrm{K}_{\mathrm{p}}$ decreases with decreasing $\alpha$. 


\section{Ground surface slope $\beta$}

The relation between $K_{p}$ and $\beta$ is plotted and shown Fig (8), it is clear that with increasing $\beta$ the value of $K_{p}$ increases, and decreases with decreasing $\alpha$ for constant value $\delta$. Figs (8) have the same trend for the given values of $\delta=(0.0,0.2,0.6,0.8$ and 1) $\varphi$.

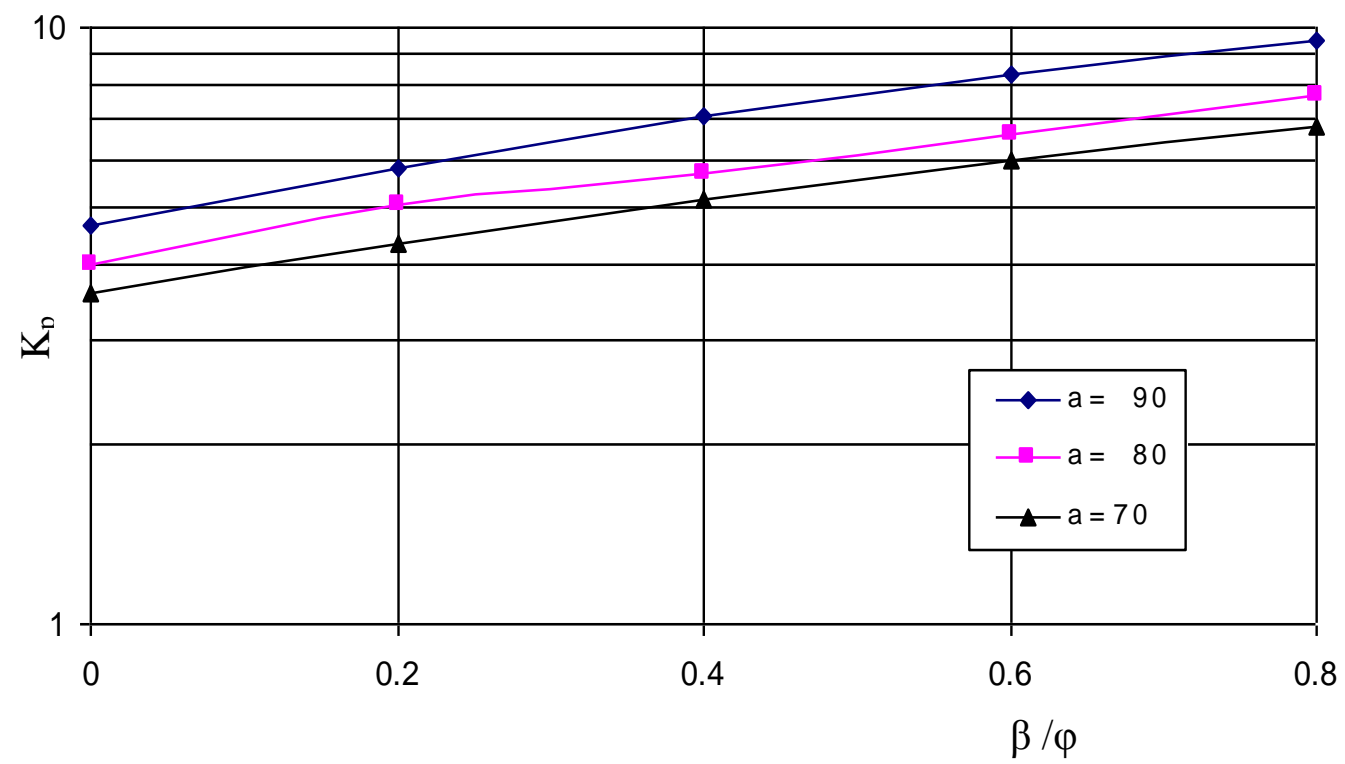

Fig.(8) $\mathrm{K}_{\mathrm{p}}$ versus $\beta / \varphi$ at $\varphi=30^{0}, \delta=0.6 \varphi$

\section{Interface angle of internal friction between wall and soil $\delta$}

The relation between $K_{p}$ and $\delta$ is plotted and shown Fig (9), it is clear that with increasing $\delta$ the value of $\mathrm{K}_{\mathrm{p}}$ increases, and decreases with decreasing $\alpha$ for constant value $\beta$. Figs (8) have the same trend for the given values of $\beta=(0.0,0.2$, and 0.8$) \varphi$.

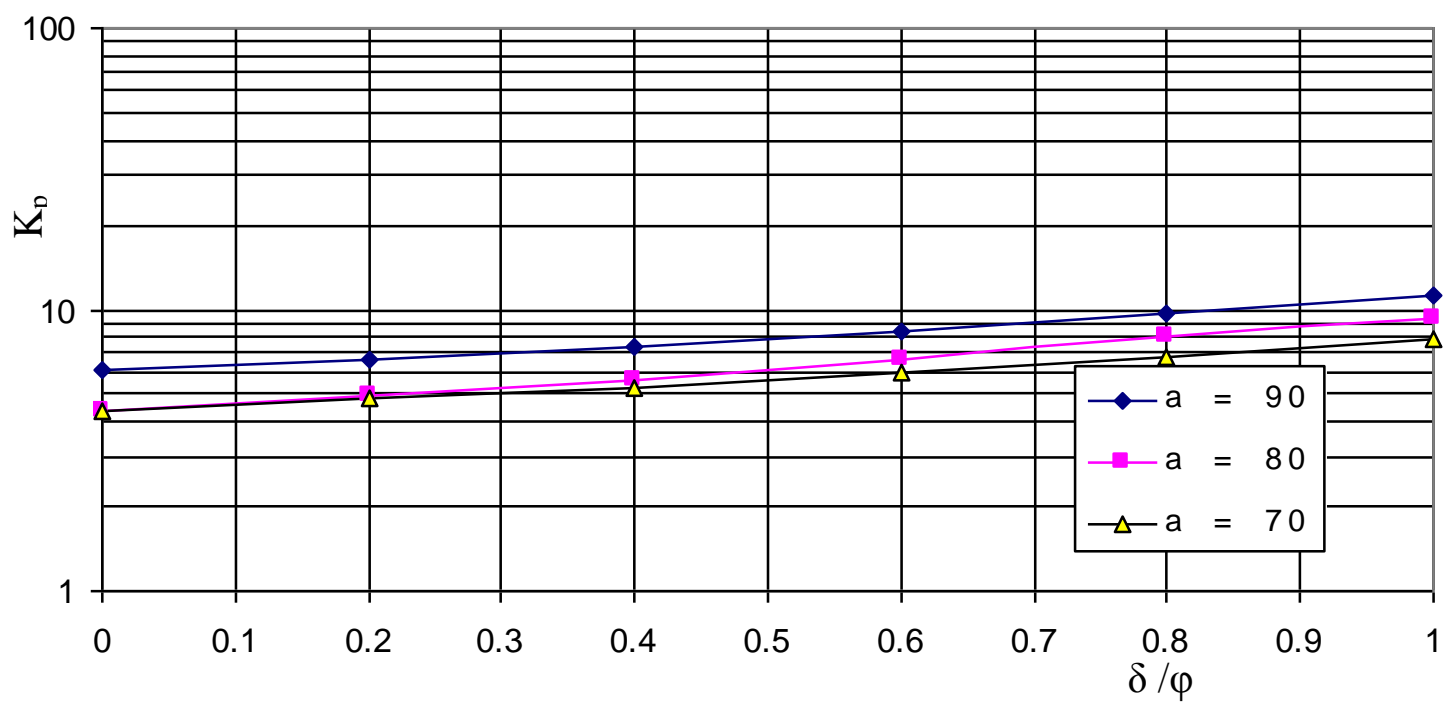

Fig.(9) $\mathrm{K}_{\mathrm{p}}$ versus $\delta / \varphi$ at $\varphi=30^{0}, \beta=0.6 \varphi$ 


\section{Inclination of the back wall face $\alpha$}

The relation between $K_{p}$ and $\alpha$ is plotted and shown Fig (10), it is clear that with increasing $\alpha$ the value of $\mathrm{K}_{\mathrm{p}}$ increases, and increases with increasing $\delta$ for constant value $\beta$. Figs (8) have the same trend for the given values of $\beta=(0.0,0.2$, and 0.8$) \varphi$.

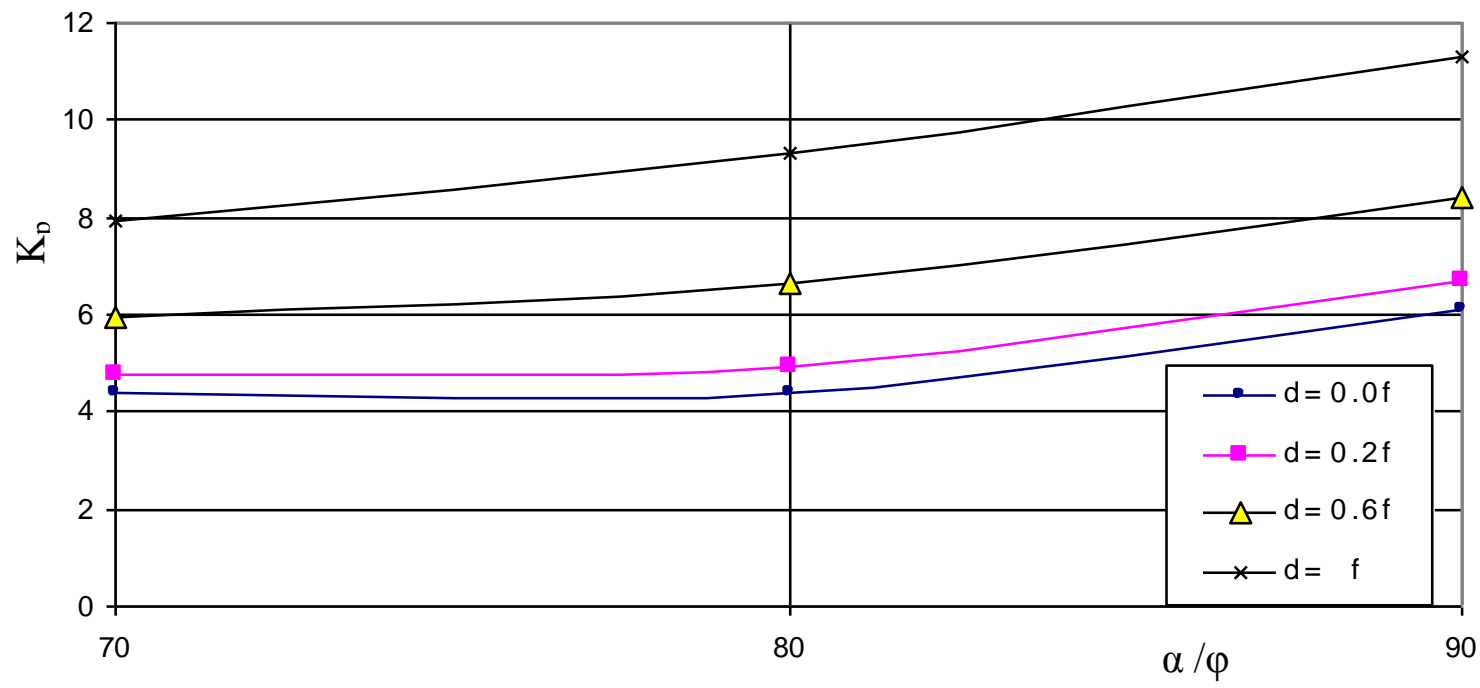

Fig.(10) $K_{p}$ versus $\alpha / \varphi$ at $\varphi=30^{0}, \beta=0.6 \varphi$

The deduced formula for calculation of $K_{p}$ corresponding $K_{p c}$ (Columb's coefficient)

Where the magnitude of friction is low so that the angle $(\delta)$ is small, the rupture surface is approximately planner. As the angle $\delta$ increases, however, the lower zone failure wedge becomes curved for values of, $(\delta>\varphi / 3)$, up to about one-third of $\varphi$. But as $\delta$ becomes larger, the error in the computed $\mathrm{K}_{\mathrm{p}}$ increasingly greater, whereby the actual passive is less than the computed value (using Eq. (1)). For larger $\delta$ analysis of force resulting from passive pressure should be based on a curved surface of rupture. When $\varphi$ $<20^{\circ}$ the difference between planner and curve surface failure little and may be neglect. In this section we will try found the relation between $\mathrm{k}_{\mathrm{p}}$ and $\mathrm{K}_{\mathrm{pc}}$ for $\left(\delta>\varphi / 3, \varphi>20^{\circ}\right)$ with different anther study parameters.

Based on data recorded in tables 1, 2 and 3 and values of $\mathrm{K}_{\mathrm{pc}}$ (Columb's coefficient) which computed using Eq. (1)

The relation between $K_{p} / K_{p c}$ for different values of $\varphi$ at certain $\delta, \beta$ and $\alpha$ may be represented by the following expression:-

$K_{p} / K_{p c}=-\mathrm{a} \tan (\varphi)+\mathrm{b}$

Where $\mathrm{a}$ and $\mathrm{b}$ are coefficient obtained by regression formula depend on on $\delta, \alpha$ and $\beta$ are listed in Tables 4 and 5 respectively. 
Table 4 Coefficient a

\begin{tabular}{|l|l|l|l|l|}
\hline \multicolumn{5}{|c|}{$\alpha=90^{\circ}$} \\
\hline \multirow{2}{*}{$\beta / \varphi$} & \multicolumn{5}{|c|}{$\delta / \varphi$} \\
\cline { 2 - 5 } & 0.4 & 0.6 & 0.8 & 1.0 \\
\hline 0.0 & 0.37 & 0.647 & 1.136 & 1.456 \\
\hline 0.2 & 0.638 & 1.024 & 1.294 & 1.63 \\
\hline 0.4 & 1.035 & 1.283 & 1.61 & 1.907 \\
\hline 0.6 & 0.766 & 1.062 & 1.287 & 1.594 \\
\hline 0.8 & 1.578 & 1.826 & 1.859 \\
\hline \multicolumn{5}{|c|}{$\alpha=80^{\circ}$} \\
\hline 0.0 & 0.173 & 0.378 & 0.639 & 1.07 \\
\hline 0.2 & 0.419 & 0671 & 1.068 & 1.402 \\
\hline 0.4 & 0.713 & 1.08 & 1.401 & 1.668 \\
\hline 0.6 & 1.102 & 1.409 & 1.659 & 1.893 \\
\hline 0.8 & 1.422 & 1.652 & 1.868 & 2.044 \\
\hline \multicolumn{5}{|c|}{$\alpha=70^{\circ}$} \\
\hline 0.0 & 0.065 & 0.219 & 0.405 & 0.676 \\
\hline 0.2 & 0.262 & 0.447 & 0.697 & 1.093 \\
\hline 0.4 & 0.491 & 0.734 & 1.104 & 1.441 \\
\hline 0.6 & 0.788 & 1.127 & 1.455 & 1.677 \\
\hline 0.8 & 1.171 & 1.47 & 1.676 & 1.746 \\
\hline
\end{tabular}

Table 5 Coefficient b

\begin{tabular}{|l|l|l|l|l|}
\hline \multicolumn{5}{|c|}{$\alpha=90^{\circ}$} \\
\hline \multirow{2}{*}{$\beta / \varphi$} & \multicolumn{5}{|c|}{$\beta / \varphi$} \\
\cline { 2 - 5 } & 0.4 & 0.6 & 0.8 & 1.0 \\
\hline 0.0 & 1.132 & 1.20 & 1.386 & 1.449 \\
\hline 0.2 & 1.187 & 1.293 & 1.33 & 1.395 \\
\hline 0.4 & 1.302 & 1.323 & 1.380 & 1.419 \\
\hline 0.6 & 1.288 & 1.323 & 1.325 & 1.369 \\
\hline 0.8 & 1.354 & 1.366 & 1.285 \\
\hline \multicolumn{5}{|c|}{$\alpha=80^{\circ}$} \\
\hline 0.0 & 1.127 & 1.163 & 1.220 & 1.392 \\
\hline 0.2 & 1.204 & 1.247 & 1.364 & 1.436 \\
\hline 0.4 & 1.285 & 1.378 & 1.440 & 1.469 \\
\hline 0.6 & 1.40 & 1.447 & 1.465 & 1.474 \\
\hline 0.8 & 1.456 & 1.458 & 1.454 & 1.439 \\
\hline \multicolumn{5}{|c|}{$\alpha=70^{\circ}$} \\
\hline 0.0 & 1.177 & 1.176 & 1.198 & 1.263 \\
\hline 0.2 & 1.241 & 1.247 & 1.291 & 1.408 \\
\hline 0.4 & 1.303 & 1.331 & 1.428 & 1.501 \\
\hline 0.6 & 1.385 & 1.454 & 1.518 & 1.523 \\
\hline 0.8 & 1.495 & 1.53 & 1.523 & 1.454 \\
\hline
\end{tabular}




\section{Application of the program and comparison with others}

Some examples were solved using program and are compared with the references given in Figs. (11-14). Fig.(11) shows the) $\mathrm{K}_{\mathrm{p}}$ versus $\varphi$ at $\alpha=90^{\circ}, \beta / \varphi=0.0, \delta / \varphi=0.6$ using different method. It is clear that where the magnitude of friction is low so that the angle $(\delta)$ is small the $K_{p}$ is the same for different methods. After that clear difference between planner surface and log-spiral surface failure

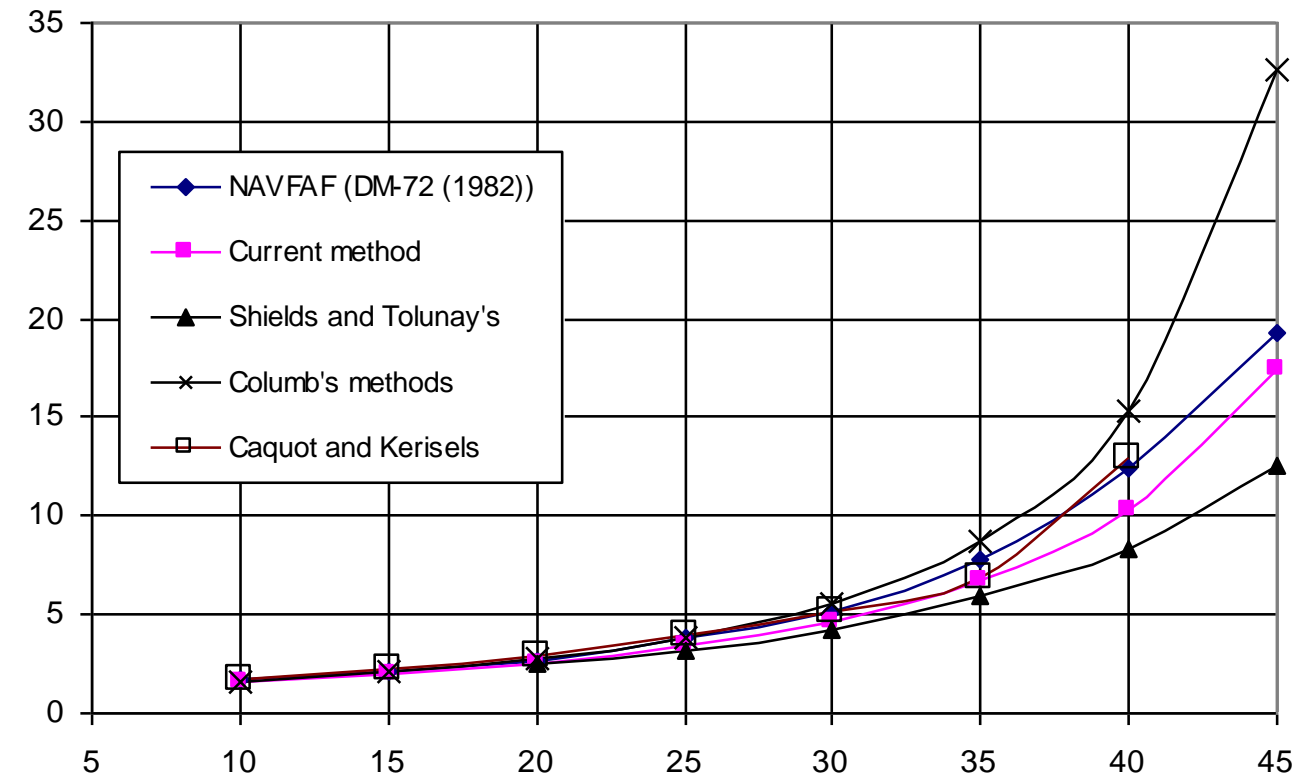

Fig. (11) $\mathrm{K}_{\mathrm{p}}$ versus $\varphi$ at $\alpha=90^{\circ}, \beta / \varphi=0.0, \delta / \varphi=0.6$ using different method

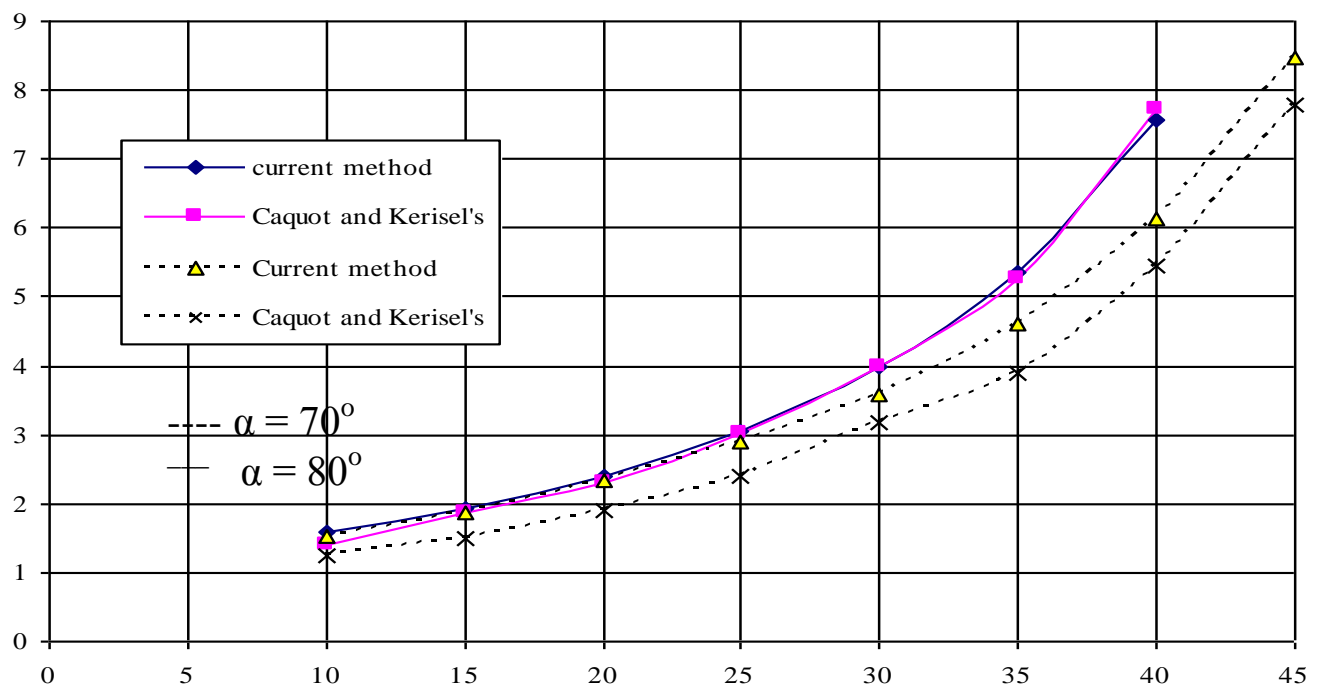

Fig.(12) $K_{p}$ versus $\varphi$ at $\alpha=80^{\circ}, 70^{\circ}, \beta / \varphi=0.0, \delta / \varphi=0.6$ using different method 


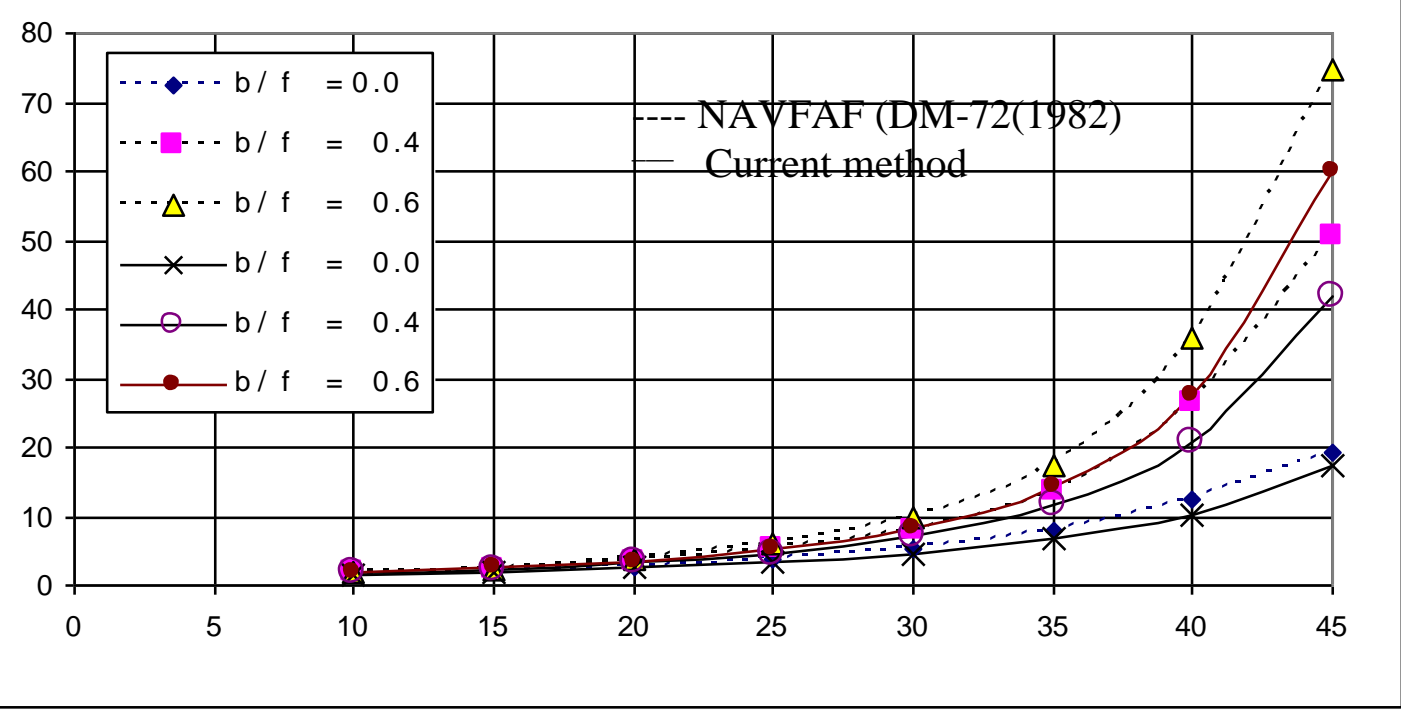

Fig.(13) $\mathrm{K}_{\mathrm{p}}$ versus $\varphi$ at $\alpha=90^{\circ}, \delta / \varphi=1.0$ using different method

\section{Conclusions}

The main conclusions of the present study can be drawn as follows:-

- Coefficient of the passive earth increasing with increases angle of internal friction of soil.

- Coefficient of the passive earth increasing with increases $\delta / \varphi$.

- Coefficient of the passive earth increasing with increases $\beta / \varphi$.

- Coefficient of the passive earth decreasing with decreases $\alpha$.

- Where the magnitude of friction is low so that the angle $(\delta)$ is small, the rupture surface is approximately planner. As the angle $\delta$ increases, however, the lower zone failure wedge becomes curved for values of, $(\delta>\varphi / 3)$. But as $\delta$ becomes larger, the error in the computed $\mathrm{K}_{\mathrm{p}}$ increasingly greater, whereby the actual passive is less than the computed value (using Columb's theory)). For larger $\delta$ analysis of force resulting from passive pressure should be based on a curved surface of rupture. When $\varphi<20^{\circ}$ the difference between planner and curve surface failure little and may be neglect.

\section{References}

1. AmrRadwan, Fundamentals of Soil Mechanics, (2006), Electronic version.

2. Arpad Kezdi and Laszlo Rethati, (1980) “ Handbook of Soil Mechanics " Vol. 2, Akademiai, Kiada, Budapest and Elsevier Scientific Publishing Company, Amsterdam Printed in Hungary.

3. Chandrakant S. Desai nad John T. Christion (1977) "Numerical methods in geotechnical engineering" McGraw Book Company-New York. 
4. Coulomb CA. Essaisurune application des règles des maximasetminimas à quelquesproblèmes de statiquerelatifs à l'architecture. Mém. acad. roy. pres. divers savanta, vol. 7, 1776, Paris [in French]

5. Caquot,A.andKérisel, ,J. Tables for the calculation of earth pressure, active pressure and bearing capacity of foundations, Gauthier-Villard, Paris (1948).

6. Das., B. M.Principles of Geotechnical Engineering.,Books/ Cole Engineering Division, Monterey, California (2001)

7. Duncan, J. M. and Mokwa, R. L. (2001), Passive earth pressure: Theories and tests,ASCE J. Geotech. Geoenviro. Engng 127, No. 3, 248-257

8. D.-Y. Zhu, Q.-H. Qian and C.F. Lee, Active and passive critical slip fields for cohesionless soils and calculation of lateral earth pressures. Géotechnique, 515 (2001).

9. El-shafay, U. M. Soil Mechanics Part 2, DarEl-RatebUniversities, Beirut 1990. Arabic version

10. G.R. Martin and L. Nad Yan, Modellingpassiveearth pressure for bridge abutments. Earthquake-induced movements and seismic remediation of existing foundations and abutments. Geotech Spec Publ, 55 (1995), pp. 1-16.

11. H. Rahardjo and D.G. Fredlund, General limit equilibrium method for lateral earth forces. Can Geotech J, 211 (1984).

12. Iqbal H. Khan, "A Text Book of Geotechnical Engineering", New Delhi-110001, (1998).

13. Janbu, N. (1957). "Earth pressure and bearing capacity calculations by generalized procedure of slices," Proc. 4th Int. Conf. on Soil Mechanics and Foundation Eng., Vol. 2, pp. 207-213.

14. J. Graham, Calculation ofearth pressure in sand. Can Geot J, 84 (1971).

15. Kérisel J, Absi E. Tables de pousséeet de butée des terres. 3rd ed. Presses de l'ÉcoleNationale des Ponts et Chaussées, Paris, 1990

16. McCarthy David F., " Essential of soil mechanics and Foundations" Basic Geotechnics, Seventh Edition, Pearson Prentice Hall Upper Saddle Rivers, New Jersey, Columbus, Ohio, Copyright 2007 
17. N. Benmebarek, S. Benmebarek, R. Kastner and A.H. Soubra, Passive and active searth spressures in the presence of groundwater flow. Géotechnique, The Institution of Civil Engineers, London, 563 (2006), pp. 149-158.

18. R. M. El-Hansy, Solved Problems in Soil Mechanics, DarEl-RatebUniversities, Beirut ,1990.

19. Rupa, S. D. and Pise, P.J. (2008)., Effect of Arching on Passive Earth Pressure Coefficient., The $12^{\text {th }}$ International Conference of International Association of Computer Method and Advances in Geomechanics, IACMAG,1-6 October 2008 Goa, India

20. Shields, D.H. and Tolunay, A.Z. (1973). "Passive pressure coefficients by method of slices," J. Soil Mech. and Found. Div., ASCE, 99(12), 1043-1053.

21. Simth, I. M. and Griffiths, D. V. (2004), Programming the Finite Element Mothed., $4^{\text {th }}$ Edition, New York, John Wiley and Sons.

22. V.V. Sokolovski, Statics of granular media, Pergamon Press, New York (1965).

23. W.F. Chen, Limit analysis and soil plasticity, Elsevier, Amsterdam (1975)

24. W.J.M. Rankine, On the stability of loose searth, Philosophical Trans Royal Soc, London (1857 
Proceedings of the $\mathbf{9}^{\text {th }}$ ICCAE-9 Conference, 29-31 May, 2012 